\title{
DEVELOPMENT OF NEW PYRAZOLE HYBRIDS AS ANTITUBERCULAR AGENTS: SYNTHESIS, BIOLOGICAL EVALUATION AND MOLECULAR DOCKING STUDY
}

\author{
SAMEER I. SHAIKH, ZAHID ZAHEER*, SANTOSH N. MOKALE, DEEPAK K. LOKWANI \\ Y. B. Chavan College of Pharmacy, Dr. Rafiq Zakaria Campus, Aurangabad 431001, (M. S.), India \\ Email: zahidzresearch2@gmail.com
}

Received: 03 Jun 2017 Revised and Accepted: 21 Sep 2017

\section{ABSTRACT}

Objective: Synthesis of new 1, 3-diphenyl pyrazole derivatives 9 (a-f) and 10(a-f) using molecular hybridization approach and evaluation of their antitubercular and cytotoxic studies.

Methods: The structures of synthesized compounds were confirmed by ${ }^{1} \mathrm{H}$ NMR, ${ }^{13} \mathrm{C}$ NMR and mass spectra. The antitubercular activity of compounds and standard drugs were assessed against Mycobacterium tuberculosis using Microplate alamar blue assay (MABA). The cytotoxic activities were performed by Sulforhodamine B (SRB) assay. The molecular docking and in silico ADME prediction studies were also performed by using Schrodinger.

Results: The results reveal that compounds 9c, 9d, $10 \mathrm{c}$ and $10 \mathrm{~d}$ exhibited substantial antitubercular potential with MIC<20 $\mu \mathrm{M}$. The cytotoxic studies revealed that active compounds (9c, 9d, 10c and 10d) are non-toxic to HeLa cancer cell lines with the selectivity index>10. The molecular docking study was performed to study the binding orientation and affinity of synthesized compounds for InhA enzyme.

Conclusion: The study explored that 1, 3-diphenyl pyrazole hybrid coupled with well-known antitubercular drugs could be a potential lead for antitubercular agents. In silico molecular docking, study helps to identify their corresponding intermolecular ligand-protein interactions with target enzyme. Also, ADME prediction studies revealed that the compounds were in acceptable range to have good pharmacokinetic parameters.

Keywords: Pyrazole, Antitubercular activity, Cytotoxicity, Molecular docking

(C) 2017 The Authors. Published by Innovare Academic Sciences Pvt Ltd. This is an open-access article under the CC BY license (http://creativecommons.org/licenses/by/4.0/) DOI: http://dx.doi.org/10.22159/ijpps.2017v9i11.20469

\section{INTRODUCTION}

Tuberculosis (TB) is a re-emerging global health threat caused by an infectious bacillus called Mycobacterium tuberculosis and is the second largest killer disease caused by a single infectious agent after the human immunodeficiency virus (HIV) [1]. World Health Organization (WHO) Global Tuberculosis Report 2016 suggested that, in 2015, there were an estimated 10.4 million new tuberculosis cases worldwide. People living with HIV accounted for 1.2 million (11\%) of all new tuberculosis cases [2].

World Health Organization (WHO) promoted a comprehensive tuberculosis management program known as DOTS (Directly Observed Treatment, Shortcourse). DOTS therapy involves the use of four first-line agents as isoniazid, ethambutol, pyrazinamide, and rifampicin for six months [3].

Despite notable progress in antitubercular agents, multi-drug resistance tuberculosis (MDR-TB), extremely drug resistance tuberculosis (XDR-TB) and HIV co-infection are the major hurdles in control of tuberculosis infection [4]. Therefore, the discovery and development of new chemical entities with a novel mechanism of action, safe and efficacious drugs, and shorter duration of treatment are the desperate needs for infectious diseases research programs. Pioneering scientists had reported pyrazole and its derivatives for an extensive range of pharmacological activities such as antipyretic, analgesic, antimicrobial, anticancer, antitubercular, antiviral, antihypertensive, antioxidant, antidepressant, and anxiolytic [5-7]. Rangappa S. Keri et al. reviewed and discussed the possible structure-activity relationship of different types of pyrazole scaffold for designing of better antitubercular agents [8]. Synthetic analogues of pyrazole are known to exhibit significant antitubercular activity especially 1,3-diphenyl pyrazole motif is known to be a potent antitubercular agent (fig. 1) [9]. Even though isoniazid (INH) has been the most widely used treatment for tuberculosis and its latent infections, it suffers from two pitfalls as enzymatic acetylation of isoniazid by Nacetyltransferase (NATs) and it's associated liver toxicity. So, blocking $\mathrm{N}$-acetylation via chemical modification of $\mathrm{N}$-terminal of isoniazid makes it to be more effective and less hepatotoxic than isoniazid [10]. Linezolid is recommended by the WHO to treat drug-resistant tuberculosis [11]. The study also found that it is potentially important for patients with XDR-TB. It acts by inhibiting protein synthesis at an early stage of translation [12]. 3-Fluoro-4-morpholinoaniline, a bioactive segment of linezolid plays a very crucial role in the antitubercular activity. 3-Fluoro group attached to phenyl ring enhances the potency while morpholine ring improves pharmacokinetic and water solubility of linezolid [13].

The molecular hybridization approach is one of the most valuable structural modification tools useful for the discovery of ligands and prototypes. Recently, the emerging interest to discover hybrid molecules resulting from the combination of pharmacophoric moieties of different known lead compounds has been developed with a new hope for the treatment of multifactorial diseases [14].

In the light of above consideration, it seems rational to combine the pharmacophoric potential of the two well-known antitubercular agents like isoniazid and linezolid with one core scaffolds, pyrazole (fig. 1). Finally, these hybridized molecules were evaluated for antitubercular and cytotoxicity studies. The molecular docking study was performed to determine the possible mechanism of action of titled compounds by which they exert antitubercular activity. The in silico molecular docking study helps to identify their corresponding intermolecular ligand-protein interactions with target enzyme to set a basis for mycobacterial inhibition. In addition to this, absorption, distribution, metabolism, and excretion (ADME) prediction studies were also performed to explore the results. 


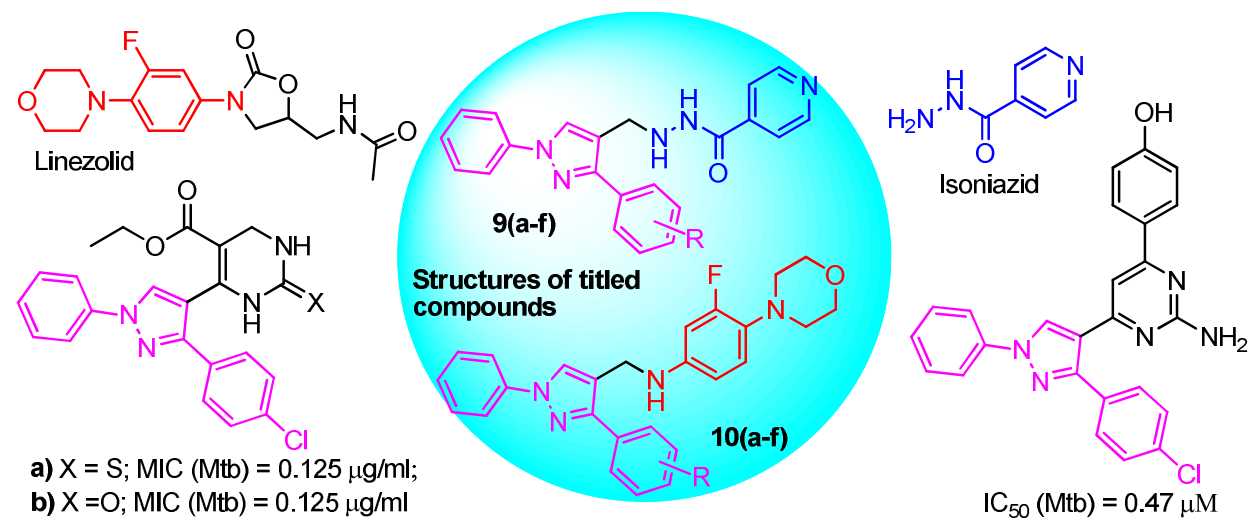

Fig. 1: Pharmacophores derived from structurally related and well known antitubercular agents

\section{MATERIALS AND METHODS}

\section{Materials}

All the solvents and reagents were used as obtained from the supplier or recrystallized/redistilled unless otherwise stated. The progress of the reaction was monitored by thin layer chromatography (TLC) using silica gel-G pre-coated aluminium plates (Merck) and visualized under UV light. Melting points were measured in open capillary tubes and uncorrected. The synthesized compounds were characterized by spectral analysis like ${ }^{1} \mathrm{H}$ NMR and ${ }^{13} \mathrm{C}$ NMR and Mass spectroscopy. The nuclear magnetic resonance ${ }^{1} \mathrm{H}$ NMR and ${ }^{13} \mathrm{C}$ NMR spectra were recorded with a Bruker DRX-400 $\mathrm{MHz}$ and Bruker DRX-100 MHz NMR spectrometer. Chemical shifts $(\delta)$ are reported in parts per million (ppm). The mass spectra were recorded under ESI mode on Waters Micromass equipment (model Q-TOF micro).

General procedure for synthesis of $N^{\prime}-((3-(4)-s u b s t i t u t e d$ phenyl)-1-phenyl-1 $H$-pyrazol-4-yl) methylen) isonicotinohydrazide $7(\mathrm{a}-\mathrm{f})$ and $\mathrm{N}$-((3-(4-substituted phenyl)-1-phenyl-1 $\mathrm{H}$ pyrazol-4-yl) methyenel)-3-fluoro-4-morpholinoaniline 8(a-f)

A mixture of substituted 3-aryl-1-phenylpyrazol-4-carbaldehydes 4(af) $(1.0 \mathrm{mmol})$ and isoniazid $5(1.0 \mathrm{mmol})$ or 3-fluoro-4morpholinoaniline $6(1.0 \mathrm{mmol})$ was dissolved in absolute ethanol (20 $\mathrm{ml}$ ) and heated under reflux for $6-8 \mathrm{~h}$ in the presence of glacial acetic acid $(2.0 \mathrm{mmol})$ as a catalyst. Then, the reaction mixture was poured in ice-cold water and filtered under suction; the precipitate thus obtained was washed with water and recrystallized from ethanol.

General procedure for synthesis of $N^{\prime}-((3-(4)-s u b s t i t u t e d$ phenyl)-1-phenyl-1H-pyrazol-4-yl) methyl) isonicotinohydrazide 9(a-f) and $N$-((3-(4-substitutedphenyl)-1-phenyl-1Hpyrazol-4-yl) methyl)-3-fluoro-4-morpholinoaniline 10(a-f)

Corresponding imines $7(\mathrm{a}-\mathrm{f})$ and $8(\mathrm{a}-\mathrm{f})(0.01 \mathrm{mmol})$ were dissolved in absolute methanol (10-15 ml) and placed in a two-necked flask fitted with two glass stoppers and a reflux condenser. This solution was warmed with continuous stirring. To this was added an equimolar amount of solid sodium borohydride (NaBH4). The portion-wise addition was made through one of the necks of the flask. If the reaction became too vigorous, the flask was moved to room temperature. When the initial reaction had subsided, the contents of the flask were refluxed for $15 \mathrm{~min}$ and then cooled. The precipitate of secondary amine thus formed was collected, washed with water, and dried. Then the compounds were recrystallized using methanol.

\section{$N^{\prime}$-((1,3-diphenyl-1H-pyrazol-4-yl)methyl)isonicotinohydrazide} (9a)

Pale yellow solid; Yield $=86 \%$; m. p. $=152-154{ }^{\circ} \mathrm{C}$; $\mathrm{R}_{\mathrm{f}}$ value $=0.56 ;{ }^{1} \mathrm{H}$ NMR $\left(\mathrm{CDCl}_{3}, 400 \mathrm{MHz}, \delta \mathrm{ppm}\right): 2.98\left(\mathrm{~s}, 1 \mathrm{H},-\mathrm{CH}_{2}-\mathrm{NH}-\right), 3.92$ (s, $2 \mathrm{H},-$ $\mathrm{CH}_{2}$ ), 7.52 (s, 1H,-CH-of Pyrazole), 7.47-7.83 (m, 10H, Ar-H), 7.72 (s, $1 \mathrm{H},-\mathrm{NH}-\mathrm{C}=0), 7.90-8.79\left(\mathrm{~m}, 4 \mathrm{H}\right.$, pyridine-H); ${ }^{13} \mathrm{C} \mathrm{NMR}\left(\mathrm{CDCl}_{3}, 100\right.$ $\mathrm{MHz}, \delta$ ppm): 49.63, 120.17, 121.05, 125.27, 126.55, 128.53, 128.97,
129.48, 130.93, 131.04, 131.22, 137.87, 137.87, 140.31, 150.63, 154.73, 164.03; $\mathrm{m} / \mathrm{z}=370.25(\mathrm{M}+1)$ (\% Mol. Wt.: 99.70).

$N^{\prime}$-((3-(4-chlorophenyl)-1-phenyl-1H-pyrazol-4-yl)methyl) isonicotinohydrazide $(9 \mathrm{~b})$

Yellow solid; Yield $=92 \% ; \mathrm{m} . \mathrm{p}=185-187^{\circ} \mathrm{C} ; \mathrm{R}_{\mathrm{f}}$ value $=0.60 ;{ }^{1} \mathrm{H}$ NMR $\left(\mathrm{CDCl}_{3}, 400 \mathrm{MHz}, \delta \mathrm{ppm}\right): 3.14\left(\mathrm{~s}, 1 \mathrm{H},-\mathrm{CH}_{2}-\mathrm{NH}-\right), 3.90\left(\mathrm{~s}, 2 \mathrm{H},-\mathrm{CH}_{2}-\right)$, 7.43-7.83 (m, 9H, Ar-H), 7.56 (s, 1H,-CH-of pyrazole), 7.73 (s, 1H,NH-C $=0)$, 7.89-8.79 (m, 4H, pyridine-H); [13]C NMR $\left(\mathrm{CDCl}_{3}, 100\right.$ $\mathrm{MHz}, \delta \mathrm{ppm}): 49.63,120.17,121.05,125.27,126.55,129.15,129.48$ $130.89,131.02,131.22,134.00,137.87,140.31,150.63,154.73$ 164.03; $\mathrm{m} / \mathrm{z}=404.60(\mathrm{M}+1)$ (\% Mol. Wt.: 99.63).

\section{$N^{\prime}$-((3-(4-fluorophenyl)-1-phenyl-1 $H$-pyrazol-4-yl)methyl) isonicotinohydrazide (9c)}

Dark-yellow solid; Yield $=90 \%$; m. $p=208-210{ }^{\circ} \mathrm{C}$; Rf value $=0.54 ;{ }^{1} \mathrm{H}$ NMR $\left(\mathrm{CDCl}_{3}, 400 \mathrm{MHz}, \delta \mathrm{ppm}\right): 2.87$ (s, 1H,-CH $-\mathrm{CH}-$ ), 3.92 (s, 2H,- $\mathrm{CH}_{2}-$ ), 7.387.84 (m, 9H, Ar-H), 7.51 (s, 1H,-CH-of pyrazole), 7.57 (s, 1H,-NH-C=O), 7.90-8.79 (m, 4H, pyridine-H); [13]C NMR $\left(\mathrm{CDCl}_{3}, 100 \mathrm{MHz}, \delta \mathrm{ppm}\right)$ : $49.63,116.69,116.89,120.17,121.07,125.27,126.55,128.41,128.44$ $129.48,131.22,132.32,132.40,137.87,140.31,150.63,154.73,162.94$, 164.03, 165.46; m/z=388.53 (M+1) (\% Mol. Wt: 99.64).

\section{$N^{\prime}$-((3-(4-bromophenyl)-1-phenyl-1H-pyrazol-4-yl)methyl) isonicotinohydrazide (9d)}

Brown solid; Yield $=91 \%$; $\mathrm{m} . \mathrm{p}=292-294{ }^{\circ} \mathrm{C} ; \mathrm{R}_{\mathrm{f}}$ value $=0.71 ;{ }^{1} \mathrm{H}$ NMR $\left(\mathrm{CDCl}_{3}, 400 \mathrm{MHz}, \delta \mathrm{ppm}\right): 3.86\left(\mathrm{~s}, 1 \mathrm{H},-\mathrm{CH}_{2}-\mathrm{NH}-\right), 3.91\left(\mathrm{~s}, 2 \mathrm{H},-\mathrm{CH}_{2}-\right.$ ), 7.44-7.64 (m, 9H, Ar-H), 7.56 (s, 1H,-CH-of pyrazole), 7.81-8.79 (m, $4 \mathrm{H}$, pyridine-H), $8.32(\mathrm{~s}, 1 \mathrm{H},-\mathrm{NH}-\mathrm{C}=0) ;{ }^{13} \mathrm{C}$ NMR $\left(\mathrm{CDCl}_{3}, 100 \mathrm{MHz}, \delta\right.$ ppm): 49.63, 120.17, 121.05, 123.85, 125.27, 126.55, 128.50, 129.48 129.95, 130.84, 137.87, 140.31, 150.63, 154.73, 164.03; m/z=448.64 (M+1) (\% Mol. Wt.: 99.52).

\section{$N^{\prime}$-((3-(4-nitrophenyl)-1-phenyl-1H-pyrazol-4-yl)methyl)} isonicotinohydrazide $(9 \mathrm{e})$

Dark grey solid; Yield $=82 \%$; m. $p=276-278{ }^{\circ} \mathrm{C} ; \mathrm{R}_{\mathrm{f}}$ value $=0.55 ;{ }^{1} \mathrm{H}$ NMR ( $\left.\mathrm{CDCl}_{3}, 400 \mathrm{MHz}, \delta \mathrm{ppm}\right): 3.90$ (s, $\left.1 \mathrm{H}_{-}-\mathrm{CH}_{2}-\mathrm{NH}-\right), 4.12$ (s, $2 \mathrm{H}$,$\mathrm{CH}_{2}$-), 7.44-7.50 (m, 9H, Ar-H), 7.51 (s, 1H,-CH-of pyrazole), 7.81$8.79\left(\mathrm{~m}, 4 \mathrm{H}\right.$, pyridine-H), $8.50(\mathrm{~s}, 1 \mathrm{H},-\mathrm{NH}-\mathrm{C}=0)$; [13]C NMR $\left(\mathrm{CDCl}_{3}\right.$, $100 \mathrm{MHz}, \delta \mathrm{ppm}): 49.63,120.17,121.05,123.63,125.27,126.55$, $127.40,129.48,131.22,137.87,140.31,148.87,150.63,154.73$, 164.03; $\mathrm{m} / \mathrm{z}=415.34(\mathrm{M}+1)$ (\% Mol. Wt.: 99.73).

\section{$N^{\prime}$-((3-(4-methoxyphenyl)-1-phenyl-1H-pyrazol-4-yl)methyl) isonicotinohydrazide (9f)}

Yellow solid; Yield $=85 \%$; m. $p=162-164{ }^{\circ} \mathrm{C} ; \mathrm{R}_{\mathrm{f}}$ value $=0.63 ;{ }^{1} \mathrm{H}$ NMR $\left(\mathrm{CDCl}_{3}, 400 \mathrm{MHz}, \delta \mathrm{ppm}\right.$ ): 2.87 (s, $1 \mathrm{H},-\mathrm{CH}_{2}-\mathrm{NH}-$ ), 3.81 (s, 3H,-OCH $-\mathrm{O}$ phenyl), $3.90\left(\mathrm{~s}, 2 \mathrm{H},-\mathrm{CH}_{2}-\right), 7.02-7.49(\mathrm{~m}, 9 \mathrm{H}, \mathrm{Ar}-\mathrm{H}), 7.50(\mathrm{~s}, 1 \mathrm{H},-\mathrm{CH}-\mathrm{of}$ pyrazole), 7.76-8.79 (m, 4H, pyridine- $\mathrm{H}), 7.77(\mathrm{~s}, 1 \mathrm{H},-\mathrm{NH}-\mathrm{C}=0)$; [13]C NMR $\left(\mathrm{CDCl}_{3}, 100 \mathrm{MHz}, \delta \mathrm{ppm}\right): 49.63,55.39,114.70,120.17,121.05$, $125.27,126.55,129.48,130.82,131.22,137.87,140.31,150.63$ 154.73, 161.23, 164.03; m/z=400.4 (M+1) (\% Mol. Wt.: 99.45). 
$N$-((1,3-diphenyl-1H-pyrazol-4-yl)methyl)-3-fluoro-4morpholinoaniline (10a)

Brown solid; Yield=94\%; m. $p=226-228{ }^{\circ} \mathrm{C}$; $\mathrm{R}_{\mathrm{f}}$ value $=0.64 ;{ }^{1} \mathrm{H}$ NMR ( $\left.\mathrm{CDCl}_{3}, 400 \mathrm{MHz}, \delta \mathrm{ppm}\right): 2.93-2.96\left(\mathrm{t}, 4 \mathrm{H},-\mathrm{CH}_{2}\right.$-of morpholine, $J=7.2$ $\mathrm{Hz})$, 3.72-3.75 (t, 4H,- $\mathrm{CH}_{2}$-of morpholine, $\left.J=7.2 \mathrm{~Hz}\right), 4.64\left(\mathrm{~s}, 2 \mathrm{H},-\mathrm{CH}_{2}-\right.$ ), $6.32(\mathrm{~s}, 1 \mathrm{H}, \mathrm{NH}), 6.15-7.92(\mathrm{~m}, 13 \mathrm{H}, \mathrm{Ar}-\mathrm{H}) ; 7.49(\mathrm{~s}, 1 \mathrm{H},-\mathrm{CH}-\mathrm{of}$ pyrazole), [13]C NMR $\left(\mathrm{CDCl}_{3}, 100 \mathrm{MHz}, \delta \mathrm{ppm}\right): 40.66,51.10,66.81$, $102.60,102.80,113.73,113.76,120.17,121.19,121.27,125.01$, $126.55,128.53,128.97,129.48,130.93,131.04,131.17,134.12$, $134.32,140.31,144.01,144.09,154.73,155.09,157.61 ;$ MS: $\mathrm{m} / \mathrm{z}=429.8(\mathrm{M}+1)(\%$ Mol. Wt.: 99.24).

\section{$N$-((3-(4-chlorophenyl)-1-phenyl-1H-pyrazol-4-yl)methyl)-3-} fluoro-4-morpholinoaniline (10b)

Yellowish-brown solid; Yield=94\%; $\mathrm{m} . \quad \mathrm{p}=228-230 \quad{ }^{\circ} \mathrm{C} ; \quad \mathrm{R}_{\mathrm{f}}$ value $=0.53 ;{ }^{1} \mathrm{H} \mathrm{NMR}\left(\mathrm{CDCl}_{3}, 400 \mathrm{MHz}, \delta \mathrm{ppm}\right): 2.93-2.96\left(\mathrm{t}, 4 \mathrm{H},-\mathrm{CH}_{2}-\right.$ of morpholine, $J=7.2 \mathrm{~Hz}), 3.72-3.75\left(\mathrm{t}, 4 \mathrm{H},-\mathrm{CH}_{2}\right.$-of morpholine, $J=7.2$ $\mathrm{Hz}), 4.56\left(\mathrm{~s}, 2 \mathrm{H},-\mathrm{CH}_{2}-\right), 5.89(\mathrm{~s}, 1 \mathrm{H}, \mathrm{NH}), 5.88-7.92(\mathrm{~m}, 12 \mathrm{H}, \mathrm{Ar}-\mathrm{H})$; 7.46 (s, $1 \mathrm{H},-\mathrm{CH}-\mathrm{of}$ pyrazole); $13 \mathrm{C}$ NMR $\left(\mathrm{CDCl}_{3}, 100 \mathrm{MHz}, \delta \mathrm{ppm}\right)$ : 40.66, 51.14, 66.81, 102.60, 102.80, 113.73, 113.76, 120.17, 121.19, $121.27,125.01,126.55,129.15,129.48,130.89,131.02,131.17$, $134.00,134.12,134.32,140.31,144.01,144.09,154.73,155.09$, 157.61.; MS: $\mathrm{m} / \mathrm{z}=463.3(\mathrm{M}+1)$ (\% Mol. Wt.: 99.84).

\section{3-Fluoro- $N$-((3-(4-fluorophenyl)-1-phenyl-1H-pyrazol-4-} yl)methyl)-4-morpholinoaniline (10c)

Brown solid; Yield $=89 \%$; $\mathrm{m} . \mathrm{p}=200-202{ }^{\circ} \mathrm{C}$; Rf value $=0.62 ;{ }^{1} \mathrm{H}$ NMR ( $\mathrm{CDCl}_{3}, 400 \mathrm{MHz}, \delta \mathrm{ppm}$ ): 2.93-2.96 (t, 4H,- $\mathrm{CH}_{2}$-of morpholine, $J=7.2$ $\mathrm{Hz}$ ), 3.72-3.75 (t, 4H,-CH2-of morpholine, J=7.2 Hz), 4.60 (s, $2 \mathrm{H},-\mathrm{CH}_{2}-$ ), $6.24(\mathrm{~s}, 1 \mathrm{H}, \mathrm{NH}), 6.12-7.92(\mathrm{~m}, 12 \mathrm{H}, \mathrm{Ar}-\mathrm{H}) ; 7.46(\mathrm{~s}, 1 \mathrm{H},-\mathrm{CH}-\mathrm{of}$ pyrazole); [13]C NMR $\left(\mathrm{CDCl}_{3}, 100 \mathrm{MHz}, \delta \mathrm{ppm}\right): 40.66,51.14,66.81$, $102.60,102.80,113.73,113.76,116.69,116.89,120.17,121.19$, $125.01,126.55,128.41,128.44,129.48,131.17,132.32,132.40$, $134.12,140.31,144.01,144.09,154.73,155.09,157.61$, MS: $\mathrm{m} / \mathrm{z}=447.3(\mathrm{M}+1)(\%$ Mol. Wt.: 99.43$)$.

\section{$N$-((3-(4-bromophenyl)-1-phenyl-1H-pyrazol-4-yl)methyl)-3-} fluoro-4-morpholinoaniline (10d)

Dark-brown solid; Yield=85\%; m. p. $=188-190{ }^{\circ} \mathrm{C} ; \mathrm{R}_{\mathrm{f}}$ value $=0.43 ;{ }^{1} \mathrm{H}$ NMR $\left(\mathrm{CDCl}_{3}, 400 \mathrm{MHz}, \delta \mathrm{ppm}\right): 2.93-2.96\left(\mathrm{t}, 4 \mathrm{H},-\mathrm{CH}_{2}\right.$-of morpholine, $J=7.2 \mathrm{~Hz}), 3.72-3.75\left(\mathrm{t}, 4 \mathrm{H},-\mathrm{CH}_{2}\right.$-of morpholine, $\left.J=7.2 \mathrm{~Hz}\right), 4.59(\mathrm{~s}$, $2 \mathrm{H},-\mathrm{CH}_{2}$-), 7.47 (s, $\left.1 \mathrm{H}, \mathrm{NH}\right), 7.45$ (s, $1 \mathrm{H},-\mathrm{CH}-\mathrm{of}$ pyrazole), 7.46-7.92 (m, 12H, Ar-H); [13]C NMR ( $\left.\mathrm{CDCl}_{3}, 100 \mathrm{MHz}, \delta \mathrm{ppm}\right): 40.66,51.10$, $66.81,102.60,102.80,113.73,113.76,120.17,121.19,121.27$, $123.85,125.01,126.55,128.50,129.48,129.95,130.84,131.17$, $134.12,134.32,140.31,144.09,154.73,155.09,157.61$; MS: $\mathrm{m} / \mathrm{z}=507.7(\mathrm{M}+1)(\%$ Mol. Wt.: 99.40).

\section{3-Fluoro-4-morpholino- $N$-((3-(4-nitrophenyl)-1-phenyl-1H- pyrazol-4-yl)methyl)aniline (10e)}

Dark-brown solid; Yield $=85 \%$; m. $p=188-190{ }^{\circ} \mathrm{C} ; \mathrm{R}_{\mathrm{f}}$ value $=0.56 ;{ }^{1} \mathrm{H}$ NMR ( $\left.\mathrm{CDCl}_{3}, 400 \mathrm{MHz}, \delta \mathrm{ppm}\right): 2.93-2.96\left(\mathrm{t}, 4 \mathrm{H},-\mathrm{CH}_{2}\right.$-of morpholine, $J=7.2 \mathrm{~Hz}$ ), 3.72-3.75 (t, 4H,- $\mathrm{CH}_{2}$-of morpholine, $\left.J=7.2 \mathrm{~Hz}\right), 4.59(\mathrm{~s}$, $2 \mathrm{H},-\mathrm{CH}_{2}$ ) $, 6.15(\mathrm{~s}, 1 \mathrm{H}, \mathrm{NH}), 7.52$ (s, $1 \mathrm{H},-\mathrm{CH}$-of pyrazole), 5.98-8.24 (m, $12 \mathrm{H}, \mathrm{Ar}-\mathrm{H})$; [13]C NMR $\left(\mathrm{CDCl}_{3}, 100 \mathrm{MHz}, \delta \mathrm{ppm}\right): 40.66,51.10$, $66.81,102.60,102.80,113.73,113.76,120.17,121.19,121.27$, $123.63,125.01,126.55,127.40,129.48,131.17,134.12,134.32$, $137.87,140.31,144.09,148.87,154.73,155.09,157.61$; MS: $\mathrm{m} / \mathrm{z}=474.8(\mathrm{M}+1)(\%$ Mol. Wt.: 99.65).

\section{3-Fluoro- $N$-((3-(4-methoxyphenyl)-1-phenyl-1 $H$-pyrazol-4- yl)methyl)-4-morpholinoaniline (10f)}

Pale yellow solid; Yield=90\%; m. $p=238-240{ }^{\circ} \mathrm{C}$; $\mathrm{R}_{\mathrm{f}}$ value $=0.70 ;{ }^{1} \mathrm{H}$ NMR ( $\left.\mathrm{CDCl}_{3}, 400 \mathrm{MHz}, \delta \mathrm{ppm}\right): 2.93-2.96\left(\mathrm{t}, 4 \mathrm{H},-\mathrm{CH}_{2}\right.$-of morpholine, $J=7.2 \mathrm{~Hz}$ ), 3.72-3.75 (t, 4H,- $\mathrm{CH}_{2}$-of morpholine, J=7.2 Hz), 3.81 (s, $3 \mathrm{H},-\mathrm{OCH}_{3}$-of Phenyl), 4.65 (s, $\left.2 \mathrm{H},-\mathrm{CH}_{2}-\right), 6.40(\mathrm{~s}, 1 \mathrm{H}, \mathrm{NH}), 7.47$ (s, $1 \mathrm{H},-$ CH-of pyrazole), 6.13-7.92 (m, $12 \mathrm{H}, \mathrm{Ar}-\mathrm{H}) ;{ }^{13} \mathrm{C}$ NMR $\left(\mathrm{CDCl}_{3}, 100 \mathrm{MHz}\right.$, $\delta \mathrm{ppm}): 40.66,51.14,55.39,66.81,102.60,102.80,113.73,113.76$, $114.70,120.17,121.19,121.27,125.01,125.75,126.55,129.48$, $130.82,131.17,134.12,134.32,140.31,144.09,154.73,155.09$, 157.61, 161.23; MS: $\mathrm{m} / \mathrm{z}=459.3$ (M+1) (\% Mol. Wt.: 99.41).

\section{Biological activities \\ Antitubercular activity}

The antitubercular activity of the synthesized compounds and standard drugs were assessed against Mycobacterium tuberculosis using Microplate alamar blue assay (MABA) [15]. This methodology is non-toxic, uses a thermally stable reagent and shows good correlation with proportional and BACTEC radiometric method. Briefly, $200 \mu \mathrm{l}$ of sterile deionized water was added to all outer perimeter wells of sterile 96 wells plate to minimized evaporation of medium in the test wells during incubation. The 96 wells plate received $100 \mu \mathrm{l}$ of the Middlebrook 7H9 broth (HiMedia, Mumbai) and serial dilution of compounds was made directly on the plate. The final drug concentrations tested were made. Plates were covered and sealed with parafilm and incubated at $37^{\circ} \mathrm{C}$ for five days. After this time, $25 \mu \mathrm{l}$ of freshly prepared 1:1 mixture of almar blue reagent and $10 \%$ tween 80 was added to the plate and incubated for $24 \mathrm{~h}$. The minimum inhibitory concentration (MIC) was defined as the minimum concentration of compound required to give complete inhibition of bacterial growth. The antitubercular screening was performed in triplet and the standard errors were all within $10 \%$ of the mean.

\section{Cytotoxicity study}

The active compounds 9c, 9d, 10c and 10d were evaluated for their in vitro cytotoxic activity against HeLa human cancer cell line, by Sulforhodamine B (SRB) assay according to the reported procedures [16]. This assay gives Growth inhibition concentration (GI50) values which were taken as the lowest concentration of the compound killing $50 \%$ of the cells.

\section{Selectivity index}

The selectivity index (SI) was calculated by dividing $\mathrm{GI}_{50}$ for human cancer cell line (HeLa) by the MIC $(\mu \mathrm{g} / \mathrm{ml})$ for in vitro activity against Mycobacterium tuberculosis. If the selectivity index (SI) is $\geq 10$, the compounds are processed further for drug development [17].

\section{Computational studies}

\section{Molecular docking study}

The molecular docking studies were performed in Maestro 9.1 using Glide (Schrodinger, LLC, New York, NY, 2015) [18]. This is an interactive molecular graphics program for docking calculations, for identification of the probable binding site of the biomolecules, and for visualizing ligand-receptor interactions. All compounds were built using Maestro build panel and optimized to lower energy conformers using Ligprep v2.4 which uses an OPLS_2005 force field. Epik v2.1was used to generate an ionized state of all compounds at target pH 7.0 \pm 2.0 . The coordinate for InhA enzyme (PDB: 2X23) [19] were taken from RCSB Protein Data Bank and prepared for docking using 'protein preparation wizard' in Maestro 9.1. Water molecules in the structures were removed and termini were capped by adding ACE and NMA residue. The bond orders and formal charges were added for hetero groups and hydrogens were added to all atoms in the structure. Side chains that are not close to the binding cavity and do not participate in salt bridges were neutralized. After preparation, the structure was refined to optimize the hydrogen bond network using an OPLS_2005 force field. This helps in the reorientation of side chain hydroxyl group. The minimization was terminated when the energy converged or the RMSD reached a maximum cutoff of $0.30 \AA$. Grids were then defined around refined structure by centring on ligand using default box size. The extra precision (XP) docking mode for all compounds was performed on a generated grid of protein structure. The final evaluation of ligandprotein binding was done with glide score (docking score). The extra precision (XP) docking mode for all compounds was performed on a generated grid of protein structure. The final evaluation of ligandprotein binding was done with glide score (docking score).

\section{RESULTS AND DISCUSSION}

\section{Chemistry}

The pyrazolyl derivatives $9(\mathrm{a}-\mathrm{f})$ and $10(\mathrm{a}-\mathrm{f})$ were synthesized as presented in Scheme 1. Initially, 3-aryl-1-phenylpyrazole-4- 
carbaldehydes 4(a-f) were synthesized from phenylhydrazones 3(af) by Vilsmeier-Haack formylation as reported by Raquib Alam et al. [20]. Then 3-aryl-1-phenylpyrazole-4-carbaldehydes 4(a-f) were condensed with isoniazid 5 and 3-fluoro-4-morpholinoaniline 6 which gives corresponding imines $7(\mathrm{a}-\mathrm{f})$ and $8(\mathrm{a}-\mathrm{f})$ respectively. The last step involves reduction amination of imines $7(\mathrm{a}-\mathrm{f})$ and $8(\mathrm{a}-\mathrm{f})$ using sodium borohydride $\left(\mathrm{NaBH}_{4}\right)$ in methanol to afford corresponding titled compounds $9(\mathrm{a}-\mathrm{f})$ and $10(\mathrm{a}-\mathrm{f})$.

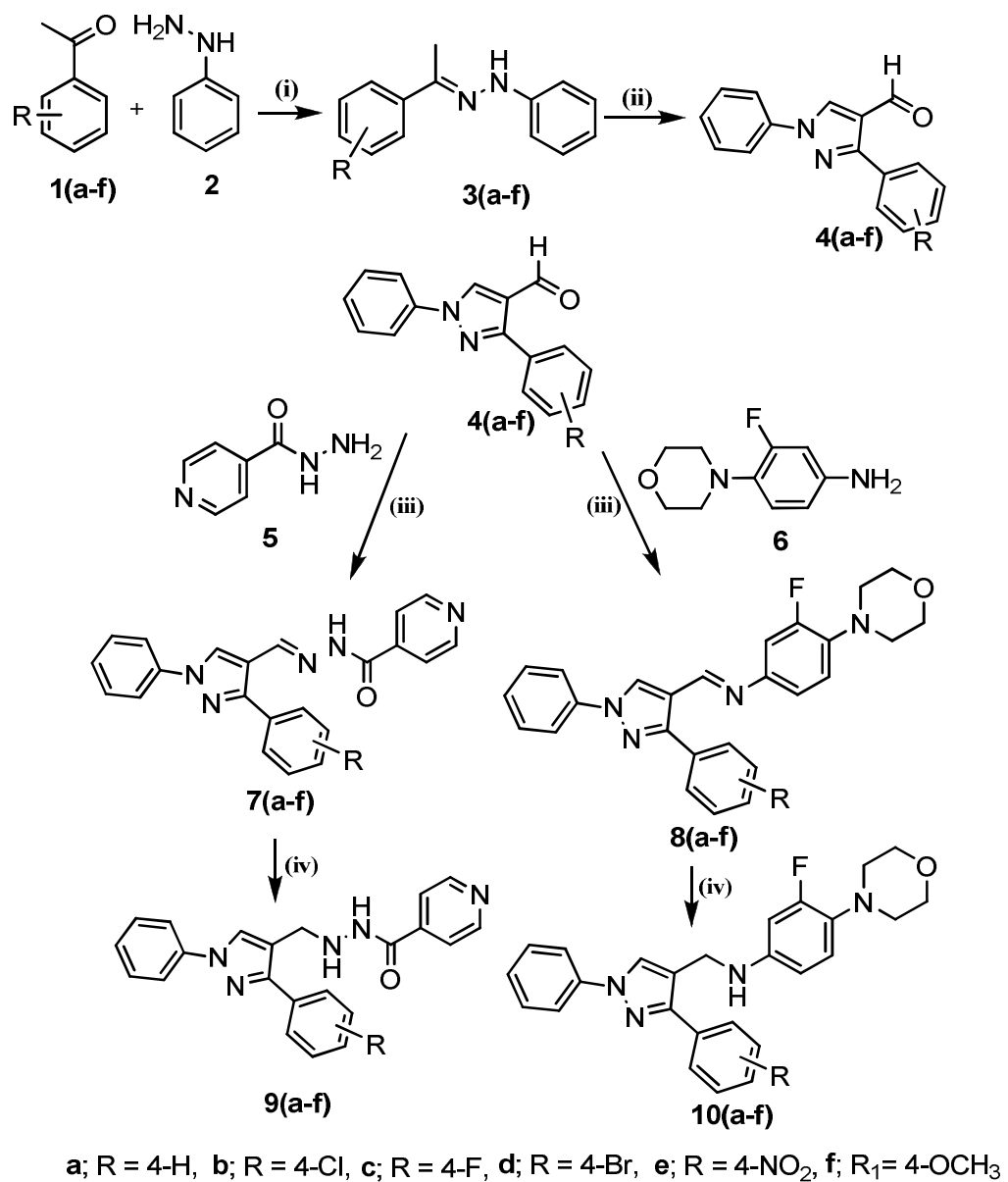

Scheme 1: General procedure for synthesis of pyrazolyl derivatives 9(a-f) and 10 (a-f); (i) EtOH, $\mathrm{H}_{2} \mathrm{SO}_{4}$, reflux; (ii) a. $\mathrm{POCl}_{3} / \mathrm{DMF}, \mathrm{80}^{\circ} \mathrm{C}$; b. $\mathrm{NaHCO}_{3} / \mathrm{H}_{2} \mathrm{O}$; (iii) EtOH, AcOH, reflux; (iv) Methanol, $\mathrm{NaBH}_{4}$

\section{Biological activity}

\section{In vitro antitubercular activity}

All pyrazole-isoniazid 9(a-f) and pyrazole-linezolid like conjugates 10 (a-f) were tested for their in vitro antitubercular activity against Mycobacterium tuberculosis H37Ra (ATCC 27294). The antitubercular activity in terms of minimum inhibitory concentration (MIC) of titled compounds and standard drugs were given in table 1 . As evident from the data, among the pyrazole-isoniazid $9(\mathrm{a}-\mathrm{f})$ conjugates two compounds 9c and 9d were found to be most active against Mycobacterium tuberculosis H37Ra having MIC $16.06 \mu \mathrm{M}$ and 13.91 $\mu \mathrm{M}$, respectively. The compound $9 \mathrm{f}$ showed good antitubercular activity with MIC $31.15 \mu \mathrm{M}$. Other compounds $9 \mathrm{~b}(\mathrm{MIC}=61.70 \mu \mathrm{M})$ and $9 \mathrm{~g}(\mathrm{MIC}=60.07 \mu \mathrm{M})$ also showed moderate antitubercular activity. Further, pyrazole-linezolid like conjugates 10(a-f) was found to possess excellent potency against Mycobacterium tuberculosis H37Ra. From this series, compound 10c and 10d exhibited excellent antitubercular effect with MIC $13.94 \mu \mathrm{M}$ and $12.30 \mu \mathrm{M}$, respectively. However, rest of compounds $10 \mathrm{~b}, 10 \mathrm{e}, 10 \mathrm{a}$, and $10 \mathrm{f}$ were also found to have moderate inhibitory effect against Mycobacterium tuberculosis. As a result of this discussion, compound $10 \mathrm{~d}(\mathrm{MIC}=12.30 \mu \mathrm{M}$ ) was found to be most potent in comparison of both the series.

\section{Structure-activity relationship (SAR)}

Observing the results, we deduce the valuable data about structureactivity correlations of the tested compounds. From the two series of compounds $9(\mathrm{a}-\mathrm{f})$ and $10(\mathrm{a}-\mathrm{f})$, the pyrazole-linezolid like conjugates 10(a-f) exhibited superior inhibitory activity than pyrazole-isoniazid 9(a-f) derivatives. The basic skeleton 1, 3-diphenyl pyrazole scaffold is supposed to have significant antitubercular activity. Further, we investigated the impact of substitution of $p$-position on the 3-phenyl of pyrazole ring. The $p$-position on the 3-phenyl of pyrazole ring substituted with electron withdrawing $(\mathrm{Cl}, \mathrm{F}, \mathrm{Br}$, and $\mathrm{NO2})$ or electron donating groups (-OCH3) were investigated. In the pyrazole-isoniazid 9(a-f) derivatives, the introduction of electron withdrawing groups like $p$-flouro $9 \mathrm{c}(\mathrm{MIC}=16.06 \mu \mathrm{M})$ and $p$-bromo $9 \mathrm{~d}(\mathrm{MIC}=13.91 \mu \mathrm{M})$ on 3-phenyl of pyrazole leads to increase activity by two folds when compared with electron donating group p-OCH3 9 f (MIC $31.15 \mu \mathrm{M}$ ).

Other electron withdrawing groups like $p$-chloro $9 \mathrm{~b}(\mathrm{MIC}=61.70 \mu \mathrm{M})$ and p-nitro 9e (MIC $=60.07 \mu \mathrm{M})$ on 3-phenyl of pyrazole showed least antitubercular activity. In pyrazole-linezolid like conjugates 10(a-f), the presence of electron withdrawing flouro group on phenyl ring largely influences the antitubercular activity $(10 \mathrm{c}$; MIC $=13.94 \mu \mathrm{M})$. Along with this flouro group, the introduction of strong electron withdrawing bromo group at $p$-position on the 3-phenyl of pyrazole ring $(10 \mathrm{~d} ; \mathrm{MIC}=12.30 \mu \mathrm{M})$ leads to significant increase in antitubercular effect. Introduction of least electron withdrawing groups like $p$-chloro $10 \mathrm{~b}(\mathrm{MIC}=26.92 \mu \mathrm{g} / \mathrm{ml}$ ) and $p$-flouro $10 \mathrm{e}(\mathrm{MIC}=$ $26.30 \mu \mathrm{M}$ ) also responsible for enhancement of antitubercular activity. The compounds with unsubstituted phenyl ring and presence of electron donating $p$-OCH3 group resulted in a decrease in activity (10a, $\mathrm{MIC}=134.70 \mu \mathrm{M} ; 10 \mathrm{a}, \mathrm{MIC}=116.22 \mu \mathrm{g} / \mathrm{ml})$. 
Table 1: In vitro antitubercular activity, cytotoxicity study and selectivity index of compounds 9(a-f) and 10(a-f)<smiles>[R]c1ccc(-c2nn(-c3ccccc3)cc2CNc2ccc(N3CCOCC3)c(F)c2)cc1</smiles>

\begin{tabular}{lllll}
\hline Entry & $\mathbf{R}$ & Anti-TB $\mathbf{M I C}(\boldsymbol{\mu M})$ & Cytotoxicity HeLa $\mathbf{G I}_{\mathbf{5 0}}(\boldsymbol{\mu} \mathbf{M})$ & Selectivity Index \\
\hline 9a & $\mathrm{H}$ & 134.70 & - & - \\
9b & $4-\mathrm{Cl}$ & 61.70 & - & - \\
9c & $4-\mathrm{F}$ & 16.06 & $>256.96$ & $>16$ \\
9d & $4-\mathrm{Br}$ & 13.91 & $>222.67$ & $>16$ \\
9e & $4-\mathrm{NO}_{2}$ & 60.07 & - & - \\
9f & $4-\mathrm{OCH}_{3}$ & 31.15 & - & - \\
10a & $\mathrm{H}$ & 116.22 & - & - \\
10b & $4-\mathrm{Cl}$ & 26.92 & - & $>16$ \\
10c & $4-\mathrm{F}$ & 13.94 & $>223.11$ & $>16$ \\
10d & $4-\mathrm{Br}_{10}$ & 12.30 & $>201.80$ & - \\
10e & $4-\mathrm{NO}_{2}$ & 26.30 & - & - \\
10f & $4-\mathrm{CCH}_{3}$ & 108.64 & - & $\mathrm{NA}$ \\
aIsoniazid & & 0.87 & $\mathrm{NA}$ & $\mathrm{NA}$ \\
aCiprofloxacin & & 9.41 & $\mathrm{NA}$ & $\mathrm{NA}$ \\
aRifampicin & & 0.70 & 0.004 & $\mathrm{NA}$ \\
bPaclitaxel & $\mathrm{NA}$ & & \\
\hline
\end{tabular}

aStandard antitubercular drug; standard anticancer drug; DPPH: 1,1-Dipheny-1-picrylhydrazyl; NA: Not applicable; NT: Not tested; Selectivity index $(\mathrm{S}$. I. $)=\left(\mathrm{GI}_{50} / \mathrm{MIC}\right) ; \mathrm{GI}_{50}=$ concentration inhibits $50 \%$ growth of cells. (Biological activities performed in the triplet. The results were with $10 \%$ of standard error mean, SEM)

\section{In vitro cytotoxicity study}

The safety profile of antitubercular active compounds with MIC $<20$ $\mu \mathrm{M}$ was assayed for in vitro cytotoxicity against HeLa cell line by Sulforhodamine B (SRB) assay method. None of the synthesized compounds 9c, 9d, 10c and $10 \mathrm{~d}$ was cytotoxic at concentration up to $200 \mu \mathrm{M}$.

\section{Selectivity index}

Table 1 observations interpret that, the screened compounds 9c, 9d, $10 \mathrm{c}$ and $10 \mathrm{~d}$ were shown selectivity index $>10$. This indicates that the screened compounds were further investigated for future drug development process.

\section{Computational studies}

\section{Molecular docking study}

In order to rationalize the observed antitubercular results and to get insight into the inhibition pattern, interactions of synthesized compounds were analyzed and depicted using molecular docking studies. Visual inspection of the minimum energy docked poses revealed that these derivatives snuggly fitted into the binding pocket of InhA enzyme (PDB: 2X23) making close contacts with the surrounding residues. The synthesized compounds showed good docking scores. A detailed per-residue interaction analysis between the protein and the most active compound $10 \mathrm{~d}$ only is elucidated for the sake of brevity through which we can speculate regarding the binding patterns in the cavity. The binding interaction of $10 \mathrm{~d}$ is presented in fig. 2. It showed multiple interactions with the residues in the active site, however for visibility and clarity only selected interacting residues are exhibited. The compound $10 \mathrm{~d}$ helped in the stabilization of compound by making hydrophobic interactions with amino acid residues like ILE95, PHE97, ILE202, MET103, MERT161, MET199, VAL203, LEU218, PR0193, PHE149, ILE194, ALA191, ILE21 and MET147 of InhA enzyme. Strong binding of $10 \mathrm{~d}$ with the active site of InhA enzyme is also contributed by its position in the pi-interaction in space of TYR158. On the basis of activity data and docking result, it was found that the compound $10 \mathrm{~d}$ has potential to inhibit InhA enzyme and can be processed further to develop a lead compound.
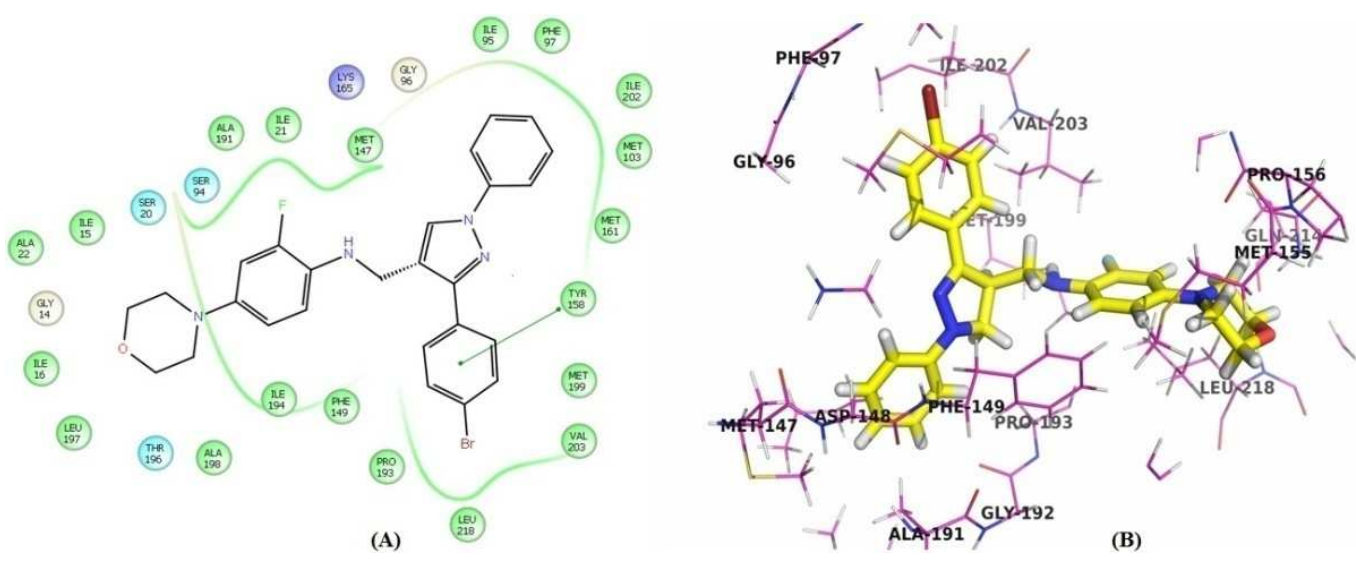

Fig. 2: (A) 2D docking pose of compound 10d; (B) 3D docking pose of compound 10d 


\section{Prediction of physicochemical and pharmacokinetic properties}

All the synthesized compounds $9(\mathrm{a}-\mathrm{f})$ and $10(\mathrm{a}-\mathrm{f})$ were evaluated for prediction of physicochemical and pharmacokinetic properties for drug-likeliness using QikProp module of Schrodinger 9.0 [21]. As per Lipinski's rule-of-five, a molecule likely to be developed as an orally active drug candidate should show no more than one violation of the four parameters such as molecular weight $(\mathrm{MW}<500)$, hydrogen bond donor (HBD; 0-6), hydrogen bond acceptor (HBA; 2-20), and partition coefficient (Q $\log P$; 1-5) [22]. Except for partition coefficient (3.52-6.88), other physicochemical properties like molecular weight (371.441-491.420), hydrogen bond donor (1-2) and hydrogen bond acceptor (4.7-6.75) found the results within their acceptable range. So, the synthesized compound has shown no more than one violation and can be developed as a good oral drug candidate. Other parameters as solvent accessible surface area (SASA; 709.441-829.983) and a number of rotatable bonds (\#rotor; $<15$; $3-5$ ) also have a great influence on the oral bioavailability of the drug molecules and found in acceptable range. Investigation of intestinal absorption, permeation, and metabolism is also greatly contributed to minimizing the clinical trial failures. Hence, predicted Caco-2 cell permeability (QPPCaco), apparent MDCK cell permeability (QPPMDCK), predicted aqueous solubility (QPlogS), percent scale human oral absorption (\%HOA), and number of likely metabolic reactions (\#metab) were also analyzed and displayed a reliable results falling in the prescribed range as shown in table 2 . From all in silico prediction of physicochemical and pharmacokinetic properties (ADME) study, these compounds could be developed as an oral active drug, making them potentially capable for antitubercular treatment.

Table 2: Physicochemical properties for the titled compounds $9(\mathrm{a}-\mathrm{f})$ and $10(\mathrm{a}-\mathrm{f})$ predicted by QikProp

\begin{tabular}{|c|c|c|c|c|c|c|c|c|c|c|c|c|}
\hline Entry & $\begin{array}{l}\text { MW } \\
(<500)\end{array}$ & $\begin{array}{l}\text { HBD } \\
(0- \\
6) \\
\end{array}$ & $\begin{array}{l}\text { HBA } \\
(2- \\
20) \\
\end{array}$ & $\begin{array}{l}\text { QlogPo/w } \\
(1-5)\end{array}$ & $\begin{array}{l}\text { SASA } \\
(300- \\
1000)\end{array}$ & $\begin{array}{l}\text { \#rotor } \\
(0-15)\end{array}$ & $\begin{array}{l}\text { No. of } \\
\text { violations } \\
(<1)\end{array}$ & $\begin{array}{l}\text { QPPCaco } \\
(>500 \\
\text { great })\end{array}$ & $\begin{array}{l}\text { QPPMDCK } \\
(>500)\end{array}$ & $\begin{array}{l}\text { QPlogS } \\
\text { (-6.5- } \\
0.5)\end{array}$ & $\begin{array}{l}\text { \% HOA } \\
(>80 \%)\end{array}$ & $\begin{array}{l}\text { \#metab } \\
(1-8)\end{array}$ \\
\hline $9 a$ & 371.441 & 2 & 6 & 4.22 & 709.411 & 4 & 0 & 857.23 & 418.833 & -5.576 & 100 & 3 \\
\hline $9 b$ & 405.886 & 2 & 6 & 4.69 & 732.779 & 4 & 0 & 879.61 & 1060.693 & -6.259 & 100 & 3 \\
\hline $9 c$ & 389.431 & 2 & 6 & 4.43 & 718.268 & 4 & 0 & 879.46 & 776.501 & -5.932 & 100 & 3 \\
\hline $9 d$ & 450.337 & 2 & 6 & 4.76 & 738.357 & 4 & 0 & 879.10 & 1134.407 & -7.153 & 100 & 3 \\
\hline $9 e$ & 416.438 & 2 & 7 & 3.52 & 754.269 & 5 & 0 & 99.065 & 40.65 & -6.09 & 83.30 & 4 \\
\hline $9 f$ & 401.467 & 2 & 6.75 & 4.98 & 829.983 & 5 & 0 & 1318.83 & 667.204 & -5.888 & 100 & 4 \\
\hline $10 a$ & 430.524 & 1 & 4.7 & 6.30 & 742.260 & 3 & 1 & 5954.59 & 5231.022 & -7.447 & 100 & 4 \\
\hline $10 \mathrm{~b}$ & 464.969 & 1 & 4.7 & 6.79 & 766.793 & 3 & 1 & 5884.19 & 10000 & -8.159 & 100 & 4 \\
\hline $10 c$ & 448.514 & 1 & 4.7 & 6.52 & 748.262 & 3 & 1 & 5910.85 & 9364.362 & -7.818 & 100 & 4 \\
\hline $10 \mathrm{~d}$ & 491.420 & 1 & 4.7 & 6.88 & 775.253 & 3 & 1 & 5982.35 & 10000 & -9.081 & 100 & 4 \\
\hline $10 \mathrm{e}$ & 475.521 & 1 & 5.7 & 5.59 & 782.232 & 4 & 1 & 701.45 & 518.474 & -7.965 & 100 & 5 \\
\hline $10 \mathrm{f}$ & 460.550 & 1 & 5.45 & 6.36 & 779.035 & 4 & 1 & 5750.95 & 5026.507 & -7.759 & 100 & 5 \\
\hline
\end{tabular}

MW-Molecular weight; HBD-Hydrogen bond donor; HBA-Hydrogen bond acceptor; QlogPo/w-Predicted octanol/water partition coefficient; SASASolvent accessible surface area; \#rotor-Number of rotatable bonds; QPPCaco-Possible CaCO cell permeability; QPPMDCK-Predicted apparent MDCK cell permeability; QPlogS-Predicted aqueous solubility; \% HOA-Percent human oral absorption; \#metab-Number of likely metabolic reactions.

\section{CONCLUSION}

In conclusion, some new structural hybrids of 1, 3-diphenyl pyrazole bearing isoniazid and linezolid like moieties were synthesized and investigated for their in vitro antitubercular activity with an anticipation of generating new structural leads. Four of the synthesized compounds (9c, 9d, 10c and 10d) possessing electron withdrawing groups such as flouro and bromo at para position were identified as the most potent antitubercular agents. The potent antitubercular activity of the most potent compounds was accompanied with a relatively low level of cytotoxicity and higher selective index. Additionally, the molecular docking study of compounds helps to estimate possible binding interactions with the active site of InhA enzyme-enzyme. The analysis of the physicochemical and pharmacokinetic properties for the titled compounds has shown that these compounds have good oral-like properties and can be developed as oral drug candidates.

\section{ACKNOWLEDGEMENT}

The authors are thankful to the Padmashree Mrs. Fatma Rafiq Zakaria Chairman, Maulana Azad Educational Trust and Principal, Y. B. Chavan College of Pharmacy, Dr. Rafiq Zakaria Campus, Aurangabad 431001 (M. S.), India for providing the laboratory facility. The author S. I. S. is very much grateful to the University Grant Commission (UGC), New Delhi for the award of a senior research fellowship. Authors are also thankful to SAIF, Punjab University, Chandigarh, India for providing spectra.

\section{AUTHORS' CONTRIBUTION}

Sameer I. Shaikh researched and wrote this overview. Zahid Zaheer and Santosh N. Mokale provided guidance, critical review and revision. Deepak K. Lokwani carried out all computational studies (Molecular docking and in silico properties prediction). All authors' read and approved the final version of this manuscript.

\section{CONFLICT OF INTERESTS}

The authors declare that there is no conflict of interest

\section{REFERENCES}

1. World Health Organization (WHO) Global Tuberculosis Report; 2014.

2. World Health Organization (WHO) Global Tuberculosis Report; 2016.

3. Dye C, Garnett GP, Sleeman K, Williams BG. Prospects for worldwide tuberculosis control under the WHO DOTS strategy. Lancet 1998;352:1886-91.

4. Calver AD, Falmer AA, Murray M, Strauss OJ, Streicher EM, Hanekom $\mathrm{M}$, et al. Emergence of increased resistance and extensively drug-resistant tuberculosis despite treatment adherence, south Africa. Emerg Infect Dis 2010;16:264-71.

5. Kumar H, Saini D, Jain S, Jain N. Pyrazole scaffold: a remarkable tool in the development of anticancer agents. Eur J Med Chem 2013;70:248-58.

6. Perka H, Prasad VVVR, Satyavadi D, Subramanian S, Boya V, Gali P. Synthesis, characterization and anti-inflammatory activity of novel pyrazole derivatives. Asian J Pharm Clin Res 2015;8:82-6.

7. Phoujdar MS, Aland GR. Molecular docking study on $1 \mathrm{~h}-(3,4 \mathrm{~d})$ pyrazolopyrimidines as cyclin-dependent kinase (cdk2) inhibitors. Int J Curr Pharm Res 2017;9:94-100.

8. Keri RS, Chand K, Ramakrishnappa T, Nagaraja BM. Recent progress on pyrazole scaffold-based antimycobacterial agents. Arch Pharm Chem Life Sci 2015;348:1-16.

9. Bhatt JD, Chudasama CJ, Patel KD. Pyrazole clubbed triazolo [1,5-a]pyrimidine hybrids as an anti-tubercular agent: synthesis, in vitro screening and molecular docking study. Bioorg Med Chem 2015;23:7711-6. 
10. Eldehna WM, Fares M, Abdel Aziz MM, Abdel Aziz HA. Design, synthesis and antitubercular activity of certain nicotinic acid hydrazides. Molecules 2015;20:8800-15.

11. http://www.tbonline.info/posts/2011/8/24/linezolid/. [Last accessed on 10 May 2017].

12. Schecter GF, Scott C, True L, Raftery A, Flood J, Mase S. Linezolid in the treatment of multidrug-resistant tuberculosis. Clin Infect Dis 2010;50:49-55.

13. Barbachyn MR, Ford CW. Oxazolidinone structure-activity relationships leading to linezolid. Angew Chem Int Ed Engl 2003;42:2010-23.

14. Fraga CAM. Drug hybridization strategies: before or after lead identification? Expert Opin Drug Discovery 2009:4;605-9.

15. Krishnasamy SK, Namasivayam V, Mathew S, Eakambaram RS, Ibrahim IA, Natarajan A, et al. Design, synthesis, and characterization of some hybridized pyrazolone pharmacophore analogues against Mycobacterium tuberculosis. Arch Pharm Chem Life Sci 2016:349;383-97.
16. Vichai V, Kirtikara K. Sulforhodamine B colourimetric assay for cytotoxicity screening. Nat Protoc 2006:1;1112-6.

17. Shaikh MH, Subhedar DD, Nawale L, Sarkar D, Khan FAK Sangshetti JN, et al. 1,2,3-Triazole derivatives as antitubercular agents: synthesis, biological evaluation and molecular docking study. Med Chem Commun 2015:6;1104-16

18. Glide v5.6 Schrodinger, LLC, New York, NY; 2015.

19. Luckner SR, Liu N, Am Ende CW, Tonge PJ, Kisker CA. Slow, tight binding inhibitor of inha, the enoyl-acyl carrier protein reductase from Mycobacterium tuberculosis. J Biol Chem 2010;285:14330.

20. Alam R, Wahi D, Singh R, Sinha D, Tandon V, Grover A, et al. Design, synthesis, cytotoxicity, HuTopoIIa inhibitory activity and molecular docking studies of pyrazole derivatives as potential anticancer agents. Bioorg Chem 2016;69:77-90.

21. QikProp 4.3 User Manual, Schrödinger Press; 2015.

22. Lipinski CA, Lombardo L, Dominy BW, Feeney PJ. Experimental and computational approaches to estimate solubility and permeability in drug discovery and development settings. Adv Drug Delivery Rev 2001;46:3-26. 